\title{
RESISTIR É PRECISO? \\ FEMINISMOS COMO FORMA DE RESISTÊNCIA ÀS OPRESSÕES
}

\author{
Elen Karla Sousa da Silva* \\ Daniel Conte
}

\begin{abstract}
RESUMO: O presente artigo objetiva refletir sobre a invisibilidade, silenciamento, luta e resistência das mulheres, sobretudo das mulheres negras, visto que há uma urgência de considerarmos a pluralidade do feminismo. Ressalta-se que a interseccionalidade entre as formas de opressão corrobora a luta coletiva das mulheres negras em suas distintas formas de resistir e nos mais variados âmbitos de poder. As mulheres negras questionaram condutas do movimento feminista, introduzindo suas categorias de luta. Em meio a essa trajetória encaram a falta de reconhecimento de seus escritos na academia, o silenciamento, os estereótipos construídos historicamente e o racismo delimitando os espaços sociais da mulher negra. Ao se defrontar com os impactos do epistemicídio, as mulheres negras fortalecem a batalha coletiva e indicam para a premência de se entender as desigualdades de gênero baseado em um todo social. Isto posto, ao revelarmos as contribuições do feminismo negro, nos esbarramos com uma realidade multifacetada, ou seja, uma realidade na qual as categorias como gênero, classe e raça devem estar disponibilizadas de maneira a se associarem para, assim, melhor colaborar para a viabilidade de execução de análises que assegurem abranger com maior exatidão a complexidade que descreve a problemática em questão. Acreditamos que discussões como essa são importantes para refletirmos por que temos que pensar no feminismo negro se o mesmo é uma pauta que abrange todas as mulheres? Precisamos pensar em um processo de socialização de pessoas negras e pessoas brancas e do lugar que essas mulheres vão ocupar não só nas relações sociais, mas também no modo de produção. Além disso, foram consideradas as inúmeras questões que abrangem a escrita de autoria feminina e o trânsito entre o silêncio e a fala. Nessa perspectiva, este artigo reunirá teóricas e estudiosas mais representativas que embasaram a pesquisa, entre elas bell hooks (2018; 2019), Collins (2019), Scott (1992), Hollanda (2019), Kilomba (2019), Perrot (1989; 2005), Ribeiro (2018), entre outras (os).
\end{abstract}

PALAVRAS-CHAVE: Representação do Feminino. Resistência. Feminismo Negro.

\section{A invisibilidade feminina}

A história das mulheres aparece como campo definível sobretudo a partir da década de 60 do século XX. O movimento dos direitos civis influenciou os estudos feministas, contudo é importante destacar que as discussões sobre a questão da mulher são evidenciadas

\footnotetext{
* Doutoranda em Letras pela Universidade Federal do Rio Grande do Sul (UFRGS). Mestre em Letras, com área de concentração em Estudos e Discurso pela Universidade Estadual do Rio Grande do Norte (UERN). ** Doutor em Literatura Brasileira, Portuguesa e Luso-africanas pela Universidade Federal do Rio Grande do Sul (UFGRS). Professor e Pesquisador da Universidade Feevale. PQ-CNPq.
} 
entre as décadas de 1920 e 1940 (SCOTT, 1992). Ressalta-se, segundo a autora, que a gênese desse campo específico de pesquisa ocorre na Europa e nos Estados Unidos, e liga-se à política, mais diretamente à política feminista, o seu apogeu nos 1960 e 1970. Isto posto, “ [...] na década de 60 , quando as ativistas feministas reivindicavam uma história que estabelecesse heroínas, prova de atuação das mulheres, e também explicações sobre a opressão e inspiração para a ação" (SCOTT, 1992, p. 64), destaca-se que a conexão entre política e história das mulheres concomitante foi complexa.

Foi dito que as feministas acadêmicas responderam ao chamado de "sua" história e dirigiram sua erudição para uma atividade política mais ampla; no início houve uma conexão direta entre política e intelectualidade. Mais tarde - em algum momento entre a metade e o final da década de 70 [...] a história das mulheres afastouse da política. Ampliou seu campo de questionamentos, documentando todos os aspectos da vida das mulheres no passado, e dessa forma adquiriu uma energia própria. (SCOT'T, 1992, p. 64)

Para Scott (1992), as contribuições são mútuas e contundentes entre o movimento feminista e a História das Mulheres e das relações de gênero, em um sistema intrincado e ativo que circundou as reivindicações das mulheres.

De acordo com Scott (1992), a expressão gênero utilizada para teorizar a questão da diferença sexual concerne-se aos contextos cultural e social, podendo desenrolar em distintos processos vinculados com categorias de raça e classe. Assim, a distinção referente ao gênero mulher e homem se fragmenta em outras diferenças no que diz respeito à raça, classe social, status financeiro, sexualidade, locais de pertencimento, entre outros, que criam essa distinção inicial. Isto posto, o que de um modo inicial requeria uma identidade singular e homogeneizadora para as mulheres, resultou em outra que favoreceu a convicção da existência de diversas identidades. Isto é, há “diferenças dentro da diferença” (SCOTT, 1992, p.88), conforme expressa a autora. Tal confirmação expôs uma discussão na qual se pode associar o gênero como categoria de análise, e que precisa ser articulada com outros condicionantes sociais, dentre os quais podemos citar classe social, lugar de pertença e raça.

Segundo Scott (1992), nos Estados Unidos o feminismo ressurgiu nos anos 1960 influenciado pelo movimento dos Direitos Civis e também pelas políticas do governo destinadas a determinar a potencialidade das mulheres. É também nesse período que faculdades e escolas de graduação começaram a incentivar mulheres a conseguirem Ph.D., proporcionando bolsas de estudo, além de auxílio financeiro. Nesse âmbito aberto pelo engajamento de mulheres, o feminismo logo surgiu para reivindicar mais auxílios para as mulheres e para denunciar as desigualdades. As feministas na academia revelavam que os preconceitos contra as mulheres ainda existiam, por mais que elas fossem credenciadas academicamente e 
profissionalmente. Organizaram-se a fim de reivindicar uma integralidade de direitos, que suas qualificações aparentemente lhes concediam.

No processo, o feminismo assumiu e criou uma identidade coletiva de mulheres, indivíduos do sexo masculino com um interesse compartilhado no fim da subordinação, da invisibilidade e da impotência, criando igualdade e ganhando um controle sobre seus corpos e sobre suas vidas. (SCOTT, 1992, p.67-68)

De acordo com Scott (1992), a História das mulheres deve ser um campo absolutamente composto de vozes unidas no sentido de preencher lacunas transmitidas por um sistema fundamentado em uma história única. Para a autora, as mulheres não podem meramente ser incluídas em universais, sem se romper com os arquétipos e hipóteses, uma vez que essa noção de história determinava em sua própria descrição a exclusão das mulheres. Se a definição masculina mantém-se na submissão feminina, então uma mudança considerável na condição da mulher reivindica uma alteração em nossa compreensão do homem.

É sabido que a fala das mulheres no âmbito nos espaços públicos e de poder foi silenciada desde tempos remotos, pois ainda era um espaço consideravelmente masculino. Michelle Perrot, em As mulheres ou os silêncios da bistória (2005), afirma que a fala e a presença femininas surgiram na história no século XIX como um caráter de inovação, pois previamente a isso o passado das mulheres era "um oceano de silêncio" (PERROT, 2005, p. 9). As mulheres foram esquecidas na obscuridade de uma vida doméstica, de reprodução, distante dos acontecimentos sociais, não sendo enxergadas como socialmente produtoras.

No início era o Verbo, mas o Verbo era Deus, e Homem. O silêncio é o comum das mulheres. Ele convém à sua posição secundária e subordinada. [...] O silêncio é um mandamento reiterado através dos séculos pelas religiões, pelos sistemas políticos e pelos manuais de comportamento. (PERROT, 2005, p. 9)

Conforme Michelle Perrot (2005), o ponto de vista feminino preocupou-se em revelar o papel das mulheres nos espaços públicos, na resistência, nas ações da mulheres geradas cotidianamente. A autora destaca que esse movimento da nova história é contemporâneo, principado aproximadamente nos anos 1970, à medida que o feminismo revelou as histórias vivenciadas por mulheres que se encontravam no anonimato, ignoradas até aquele momento. Segundo Perrot em Minha história da mulheres (2008), a busca pelas memórias do feminino no cenário público não se limita a biografias específicas, entretanto o significado coletivo do termo cumulou informações com testemunhos escritos e orais, estabeleceu espaços de memória e deu visibilidade ao "eu" das mulheres no âmbito social, no qual "toda uma educação inculcou o decoro do esquecimento de si” (PERROT, 1989, p.17). 
É importante frisar que em inúmeras sociedades o silêncio e a invisibilidade das mulheres determinavam a ordem das coisas e assegurava um contexto de tranquilidade. Conforme Perrot (2008, p.16), as mulheres ficaram por bastante tempo “[...] destinadas à obscuridade de uma inenarrável reprodução [...]. Confinadas no silêncio de um mar abissal." Nesse silêncio arraigado é fato que as mulheres não estão sozinhas, já que a maioria da humanidade está submersa, mas é sobre elas que o silêncio tem um peso maior. Além disso, há uma idealização da mulher dentro de um arquétipo de feminilidade, enquanto objeto de desejo, representada como submissa, passiva. Para Brandão (2006, p.32):

[...] a idealização da mulher se faz de tal forma que é como se ela "naturalmente" coincidisse com o objeto de desejo masculino. O temor do homem diante da mulher desejante, com o discurso próprio, acaba por calá-la, através de um estranho recurso: registrar a voz feminina via discurso masculino, aí a inscrevendo como se fosse sua própria enunciação.

A escrita possibilitou que as mulheres falassem sobre si, que rompessem o silêncio. O imaginário masculino sempre pensou o sujeito feminino e a partir disso determinavam e criavam normas que as mulheres deveriam seguir e como elas deveriam se comportar. Desse modo, ao se senhorearem da escrita, essas mulheres autorizaram a preservação de suas memórias e sobretudo um olhar adequado sobre si mesmas com base nas próprias mulheres e não por meio de uma autoria masculina.

Uma mulher conveniente não se queixa, não faz confidências, exceto, para as católicas, a seu confessor, não se entrega. O pudor é sua virtude, o silêncio sua honra, a ponto de se tornar uma segunda natureza. A impossibilidade de falar de si mesma acaba por abolir seu próprio ser, ou ao menos o que se pode saber dele. (PERROT, 2005, p. 10)

As mulheres atuam em família e, reclusas em casa, são invisíveis. Segundo Perrot (2008, p.17), “Entre os gregos, é a statis, a desordem. Sua fala em público é indecente. Que a mulher conserve o silêncio, diz o apóstolo Paulo.Porque primeiro foi formado Adão, depois Eva. E não foi Adão que foi seduzido, mas a mulher que, seduzida, caiu em transgressão". Assim, as mulheres deveriam pagar por sua falta com o seu silêncio.

O corpo feminino também era uma ameaça, intimidava. Era aconselhável que estivesse coberto com véus. Apenas os homens são encarados como indivíduos, pessoas, trazem sobrenomes que são transmitidos de geração a geração. "As mulheres não têm sobrenome e, tem apenas um nome. aparecem sem nitidez, na penumbra dos grupos obscuros (PERROT, 2008, p. 17)

Porque são pouco vistas, pouco se fala delas. As mulheres deixam poucos vestígios diretos, escritos ou materiais. Seu acesso a escrita foi tardio. Suas produções domésticas são rapidamente consumidas, ou mais facilmente dispersas. São elas mesmas que destroem, apagam esses vestígios porque os julgam sem interesse. 
Afinal, elas são apenas mulheres, cuja a vida nao conta muito. Existe até um pudor feminino que se estende à memória. Uma desvalorização das mulheres por si mesmas. Um silêncio consubstancial à noção de honra.(PERROT, 2008, p. 17)

Pela grande parte dos homens as mulheres são generalizadas. O discurso e as imagens por vezes prolixas sobre as mulheres se contrapõem com a escassez de informações mais nítidas e circunstanciadas geradas pelos homens, tais criações distanciam-se da mulher real. As mulheres são imaginadas ao invés de serem retratadas.

Nesse sentido, é por meio da escrita feminina que pode surgir o desejo da mulher, embora que ele se assente na escrita masculina. A mulher é uma personagem produzida por si mesma, por escultores, artistas, escritores, no terreno da imaginação e da ficcionalidade masculina e feminina.

O silêncio surge ao longo da história como um traço feminino, que estabelecia parte do que constituia a mulher. Além de uma idealização acerca de sua figura, é necessário refletir sobre os espaços do silêncio em que as mulheres foram retidas, consequência esta de um poderio simbólico que determinou papéis. É importante destacar que mulheres, feministas assumidas ou não, forçaram a inclusão das temáticas que dissertavam a respeito de si, nas quais relatavam suas próprias histórias, de seus ancestrais e que possibilitam compreender as motivações de várias crenças, valores, práticas sociais que oprimem, além de inúmeras maneiras de desclassificação e estigmatização. Esse passado carregado de representações hegemônicas carece que seja revisto a partir de uma nova visão, de uma nova perspectiva, portanto é necessário que se problematize.

É importante destacar, segundo Scott (1992), que a história das mulheres documentou a distinção das “culturas das mulheres" e criou uma tradição histórica para as feministas. A realidade histórica das mulheres documentadas colaborou para o discurso identitário coletivo tornando possível, nos anos 1970, o movimento das mulheres. Tal discurso compartilhou a experiência das mulheres, ainda que considerasse as diferenças sociais, destacando o denominador comum da sexualidade juntamente com os interesses e necessidades a ela relacionadas. Ademais, 
Assim, embora ocultadas por uma história e política de silenciamento, as mulheres buscaram novas maneiras para insubordinar essa condição e para resistir, transformando o silêncio em uma arma em prol de si próprias, segundo assevera Perrot (2005, p. 10):

Evidentemente, as mulheres não respeitaram essas injunções. Seus sussurros e seus murmúrios correm na casa, insinuam-se nos vilarejos, fazedores de boas ou más reputações, circulam na cidade, misturados aos barulhos do mercado ou das lojas, inflado às vezes por suspeitos e insidiosos rumores que flutuam nas margens da opinião. Teme-se a sua conversa fiada e sua tagaralice, formas, no entanto, desvalorizadas da fala. Os dominados podem sempre esquivar-se, desviar as proibições, preencher os vazios do poder, as lacunas da História.

"Enfrentar o medo de se manifestar e, com coragem, confrontar o poder continua a ser uma agenda vital para todas as mulheres" (hooks, 2019). Quando observamos a estrutura de uma sociedade patriarcal, no que consistem efetivamente os elementos da opressão masculina em relação às mulheres, pensamos que essa opressão se manifesta sobretudo na forma de uma invisibilidade desse grupo social enquanto protagonista de sua própria história. Dessa forma, as questões que envolvem as mulheres e sua perspectiva são sub-representadas no espaço público, a partir de uma invisibilidade dessa pauta. Assim, historicamente, durante séculos observamos homens falando pelas mulheres em nome das mulheres, e isso acaba fazendo com que ocorra uma subalternidade, uma sub-representação e invisibilidade da voz feminina no espaço público. Portanto, grande parte da luta feminista e da revolução que se pretende realizar através de uma articulação feminista é que as mulheres encontrem a sua própria voz e, encontrando-a, possam ocupar espaços públicos onde poderão defender os seus interesses, a sua visão de mundo, onde vão querer postular a sua presença enquanto corpo político, enquanto voz concreta.

Isto posto, essa ideia de invisibilidade e sub-representação se manifesta, entre outras formas, através dessa visão de que se pode falar pelo outro, de que se pode falar em nome de quem é oprimido, de que o homem pode falar sobre o que é a experiência das mulheres. Esses fatos são absolutamente questionados pelo feminismo, e de uma forma mais profunda pelo feminismo negro, pois uma das formas de violência estrutural e simbólica é quando você captura a voz daquele que é oprimido e pretende falar em seu nome. Dessa forma, podemos dizer que há essa captura quando um homem acha que pode falar em nome dos grupos das mulheres, ou quando um sujeito branco acha que pode falar em nome do sujeito negro sobre as lutas, as dificuldades, as opressões, as violências que esse sujeito sofre.

Conforme a filósofa e ativista Sueli Carneiro (2011), por bastante tempo o feminismo foi aprisionado por uma perspectiva eurocêntrica e universal das mulheres. As implicações disso dizem respeito à incapacidade de reconhecer as diferenças e desigualdades existentes 
no espaço feminino. Assim, as mulheres silenciadas, com seus corpos estigmatizados, vítimas de sexismo e outras opressões, permanecem na invisibilidade e silenciadas.

Nessa perspectiva, Carneiro salienta que as mulheres negras viveram uma experiência histórica distinta das mulheres brancas, uma vez que "o discurso clássico sobre a opressão da mulher não tem reconhecido, assim como não tem dado conta da diferença qualitativa que o efeito da opressão sofrida teve e ainda tem na identidade feminina das mulheres negras" (CARNEIRO, 2011, p. 1).

Uma das grandes contribuições do feminismo negro diz respeito à questão da raça pensando uma luta antirracista e revelando as implicações do racismo e sexismo que puniram as mulheres negras a uma condição atroz de exclusão, invisibilidade, silenciamento e marginalização social.

\begin{abstract}
Dentre as contribuições do feminismo negro, ocupa lugar privilegiado a incorporação da temática da saúde e dos direitos reprodutivos na agenda da luta antiracista e o reconhecimento das diferenças étnicas e raciais nessa temática. Nessa perspectiva, a luta pela inclusão do quesito cor, sobretudo nos sistemas de classificação da população, tem se constituído um desafio permanente e objeto da ação política de aguerridas ativistas [...] (CARNEIRO, 2003, p.123)
\end{abstract}

Isto posto, ratificamos a extrema importância de enegrecer o feminismo, seguindo a expressão cunhada por Carneiro (apud Hollanda, 2019, p. 273). Segundo ela, essa expressão é utilizada "para designar a trajetória das mulheres negras no interior do movimento feminista brasileiro". Observa-se que, quando o feminismo negro se afirma, ele floresce, e como perspectiva feminista muito rica, ele vai tensionar, provocando uma compreensão muito mais profunda de como a opressão ${ }^{1}$ se manifesta dentro do tecido social. Dessa maneira, a partir do feminismo negro supera-se uma visão binária do ponto de vista da opressão, ou seja, homens que oprimem mulheres, e é possível entender, assim, que existem múltiplas hierarquizações sociais que vão se sobrepor e que vão se comunicar entre si. Como exemplos podemos citar homens que oprimem mulheres e mulheres que oprimem outras mulheres, e isso vai se cruzar a partir do diálogo dos vários marcadores de diferenças sociais: gênero, classe social, raça, geração. Quando se analisa o tecido social, é possível identificar hierarquias que se sobrepõem, o que faz com que o mesmo sujeito possa simultaneamente desempenhar papéis identificados com o grupo oprimido e papéis identificados com aquele grupo que oprime.

\footnotetext{
${ }^{1}$ Opressão é um termo que descreve qualquer situação injusta em que, sistematicamente e por um longo período, um grupo nega a outro grupo o acesso aos recursos da sociedade. (COLLINS, 2009, p. 33)
} 
Nesse sentido, pode-se citar o caso da mulher branca privilegiada que, em relação ao homem, em uma sociedade patriarcal, se situa em uma posição de grupo oprimido, mas que pode desempenhar múltiplas opressões ao grupo das mulheres negras periféricas. Dessa forma, a partir desse debate, desse esclarecimento da complexidade das hierarquias sociais e de como as interseccionalidades importam para que se compreenda profundamente a raiz da desigualdade, da exclusão, da opressão e da violência, será possível iluminar um conceito muito importante, o de lugar de fala. Esse é um conceito central dentro do pensamento feminista de terceira onda, um pensamento que começa a se articular em fins dos anos 1980 e começo dos anos 1990. Esse constructo estabelece que é absolutamente fundamental que um sujeito que fala em contexto democrático tenha consciência e clareza do lugar de onde ele está falando, no sentido de que cada um carrega na sua história e no seu corpo uma teia, que é composta de opressões, mas também pode ser uma teia de privilégios.

Assim, o debate democrático só será um debate qualificado e profundo se o sujeito que se coloca nesse debate tem compreensão dessa estrutura que ele carrega, seja como grupo oprimido, seja como grupo opressor. Quando se tem essa consciência, essa honestidade democrática de saber o lugar de onde se fala, se tem como compromisso ético respeitar o lugar de fala daquele que é do grupo oprimido. Nesse contexto, não se tem mais com uma postura eticamente aceitável que um homem possa se colocar dentro de um debate democrático para falar em nome do grupo das mulheres ou que um sujeito branco possa se colocar em um debate para falar em nome do grupo representado pelos negros. Dessa forma, não teremos uma estratégia de silenciamento ou de bloqueio do debate democrático, visto que esse não é o objetivo do lugar de fala, não é impedir que as pessoas falem sobre determinados assuntos, mas que se tenha clareza de que ao falar sobre determinado assunto inevitavelmente se carrega esse horizonte de compreensão, essa história que é uma história individual, mas também é uma história coletiva e que fala através do seu discurso. Com isso situamos todos os sujeitos dentro de um debate e, ao situá-los dessa forma, teremos condições de construir uma discussão mais franca, inclusive para apontar as limitações de compreensão de perspectiva que um sujeito historicamente situado tem para abordar determinadas questões. Portanto, o objetivo desse conceito é provocar um compromisso geral e coletivo de trazer protagonismo e criar condições de falar para aqueles que foram historicamente silenciados eoprimidos.

bell hooks (2019a) argumenta sobre o incentivo à união e à empatia que respaldava a noção de opressão comum e que essa opressão estaria direcionada para a constituição de solidariedade. Slogans como "organize-se em torno da sua própria opressão" propiciaram a justificativa da qual inúmeras mulheres privilegiadas careciam para desconsiderar as 
desigualdades entre a sua condição social e a condição das demais mulheres. Se as mulheres brancas pertencentes a uma classe média conseguiram estabelecer a partir de seus interesses o centro principal do movimento feminista, fazendo uso de uma retórica que transformava sua condição sinônimo de "opressão", isso era um traço dos privilégios de raça e classe sobretudo a realidade de viverem distantes das diversas restrições que o sexismo impõe às mulheres da classe trabalhadora.

bell hooks afirma que nos últimos anos o termo "sororidade" é usado como slogan, lema ou grito de guerra e já não provoca um sentido de poder e de homogeneidade. Algumas feministas entendem que essa unidade entre as mulheres é inconcebível considerando as nossas distinções.

\begin{abstract}
Abandonar da ideia de Sororidade como expressão de solidariedade política enfraquece e desvaloriza o movimento feminista. A solidariedade fortalece a luta pela resistência. Um movimento feminista amplamente empenhado na luta contra o sexismo não é sustentável sem uma frente unida - e cabe às mulheres tomarem a iniciativa e demonstrarem o poder da solidariedade. (hooks, 2019a, p. 80)
\end{abstract}

É fato que não veremos uma transformação na sociedade de modo geral se não revelarmos que é plausível rompermos as barreiras que afastam as mulheres e que pode sim haver solidariedade entre nós. É importante pontuar que a indiferença com a irmandade foi motivada porque várias mulheres indignadas com o constante discurso em volta da opressão comum, em uma identidade compartilhada e de igualdade, rejeitaram o feminismo.

\footnotetext{
É preciso lembrar, enquanto pensarmos criticamente sobre dominação que nós todos temos a capacidade de agir de maneiras que oprimem, dominam, machucam (seja esse poder institucionalizado ou não). É preciso lembrar que, primeiro, precisamos enfrentar o opressor em potencial dentro de nós - precisamos resgatar a vítima em potencial dentro de nós. Caso contrário, não podemos ter esperança de liberdade, de ver o fim da dominação. (hooks, 2019, p. 60)
}

Cabe destacar que o feminismo negro vai ser efetivamente a corrente e a perspectiva teórica que traz esse debate com mais força, com mais sofisticação, com mais profundidade, a fim de trazer luz para evidenciar a necessidade que se tem de criar condições de presença, representação e fala daqueles que são historicamente e estruturalmente silenciados e oprimidos. Assim, o passo fundamental para a constituição da emancipação e de um protagonismo é justamente a construção de um canal no qual essa voz possa ser ouvida, e esse processo de autorecuperação da voz é um processo de fortalecimento que vem do reconhecimento do sujeito como alguém que tem um discurso, uma fala que pode ocupar, que pode disputar o espaço público, que precisa encontrar o seu lugar, que precisa ser ouvida. 
Segundo Audre Lorde (1977, p. 4),

Fomos educadas para respeitar mais ao medo do que a nossa necessidade de linguagem e definição, mas se esperamos em silêncio que chegue a coragem, o peso do silêncio vai nos afogar. O fato de estarmos aqui e que eu esteja dizendo essas palavras, já é uma tentativa de quebrar o silêncio e estender uma ponte sobre nossas diferenças, porque não são as diferenças que nos imobilizam, mas o silêncio. E restam muitos silêncios para romper.

Desse modo, observa-se que há inúmeras maneiras de silenciar alguém. Tornar invisíveis as narrativas de um sujeito é silenciá-las. Rejeitar a escuta também é silenciamento. A não inclusão de escritores (as) negros(as) nos currículos escolares que tratam de relações étnico-raciais, a título de exemplo, é silenciamento. Isto posto, o silêncio também é ideologia. Entendemos a linguagem também como instrumento de manutenção da supremacia, e situamos os mecanismos de silenciamento como processos históricos, ideológicos e simbólicos presentes no período colonial.

\section{Erguer a voz}

Erguer a voz: pensar como feminista, pensar como negra (2019), obra publicada originalmente em 1989 nos Estados Unidos é o primeiro livro em que bell hooks reivindica o pessoal como político conectado ao relato da sua história vida com a teórica. bell hooks, fundamentada no erguer a voz, descortina sua trajetória, desafia os arquétipos racistas e sexistas por meio de uma escrita, de seu discurso cotidiano e concomitantemente acadêmico.

O ato de erguer a voz, o qual é reivindicado pela autora, é mais que um mero ato de proferir palavras por meio da fala, erguer a voz se situa no âmbito da ação. É nesse sentido que "Erguer a voz tem sido e continua a ser um trabalho que encoraja leitoras e leitores, especialmente as pessoas de grupos oprimidos e explorados que lutam para romper silêncios, a encontrar e/ou celebrar o alcance da própria voz." (hooks, 2019, p.20)

Segundo bell hooks, erguer a voz para as mulheres negras:

[...] tem sido um esforço político me agarrar à crença de que há muito sobre o que nós - pessoas negras - precisamos falar, muito que é privado e que deve ser compartilhado abertamente, se for para curarmos nossas feridas (dores causadas pela dominação e exploração e opressão), se for para nos recuperarmos e conscientizarmos. (hooks, 2019, p.26)

Para bell hooks, o silêncio nos diz que ele aparece como uma "estratégia de sobrevivência", uma vez que "muitos indivíduos de grupos oprimidos aprendem a reprimir ideias, especialmente aquelas consideradas opositoras. Da escravidão em diante, as pessoas negras nos Estados Unidos aprendemos a nos resguardar em nossa fala. Dizer a coisa errada podia 
levar à punição severa ou à morte" (hooks, 2019, p. 327). Desse modo, erguer a voz se torna uma forma de nos libertamos e mudarmos da condição de objetos para sujeitos.

Isabella Baumfree nasceu em um cativeiro em Swartekill e adotou o nome Sojourner Truth. Mulher negra feminista, abolicionista, ex-escravizada e defensora dos direitos das mulheres, em 29 de maio de 1851 fez um discurso marcante a respeito da intersecção entre o sufrágio feminino e os direitos dos negros na Convenção pelos Direitos das Mulheres de Ohio, na cidade de Akron, nos Estados Unidos.

No discurso, intitulado E eu não sou uma mulher?2, Sojourner Truth argumentou que, ao mesmo tempo que a cultura estadunidense fixava mesmo que metaforicamente as mulheres brancas em um pedestal e lhes conferia certas benesses, sobretudo não praticar atividades remuneradas por consequência de uma presumida inferioridade intelectual e física, tal conduta não abarcava as mulheres negras, habituadas com o trabalho braçal.

\begin{abstract}
Bem crianças, onde existe muita confusão deve haver alguma coisa fora de equilíbrio. Eu acho que emaranhando negros do Sul e as mulheres do Norte, todos falando em direitos, o homem branco estará encrencado logo, logo. Mas sobre o que todos aqui estão falando? O homem lá adiante diz que as mulheres precisam ser ajudadas a entrar em carruagens e ser levadas sobre as valas e a ter por toda parte os melhores lugares. Ninguém nunca me ajudou a entrar em carruagens, a sair das poças de lama nem me deu qualquer lugar melhor! E não sou eu uma mulher? Olhem para mim? Olhem para meu braço! Eu lavrei a terra, plantei e juntei todo o celeiro e nenhum homem poderia me liderar! Eu não sou eu uma mulher? Eu poderia trabalhar e comer tanto quanto um homem - quando eu podia conseguir comida - e suportar o chicote tão bem quanto! E não sou eu uma mulher? Dei à luz a treze crianças e vi a maior parte delas vendidas para a escravidão e quando chorei com minha tristeza de mãe só Jesus me ouviu! E não sou eu uma mulher? Então eles falam desta coisa na cabeça; o que é isto que eles chamam? Intelecto? É isso, querido. O que é que isso tem a ver com direitos das mulheres ou dos negros? Se em minha taça não couber metade de um quarto e na sua couber um quarto não seria mesquinho você não me deixar ter minha medida toda? Então aquele homem de preto lá diz que as mulheres não podem ter tantos direitos quanto os homens porque Cristo não era mulher! De onde veio seu Cristo? De deus e de uma mulher! Os homens não tem nada a ver com ele. Se a primeira mulher que Deus fez era forte o suficiente para virar o mundo de ponta cabeça sozinha, estas mulheres juntas devem ser capazes de novamente virá-lo de volta, com o lado certo pra cima! E agora elas estão querendo fazer isso e é melhor os homens deixarem elas fazerem. Obrigado por me ouvirem e agora a velha Sojoumer não tem mais nada a dizer. (SOJOURNER, 1851 apud CARDOSO, 2012, p. 101)
\end{abstract}

No discurso de Sojourner Truth fica evidente que aquelas mulheres não falavam para todas as mulheres e sim para uma parte delas. Seu discurso é considerado por várias feministas negras norte-americanas como uma das bases do feminismo negro, principalmente por expor as bases do pensamento feminista negro. Isso revela que desde bastante tempo há um

\footnotetext{
${ }^{2}$ E eu não sou uma mulher? também é o título do primeiro livro de bell hooks, publicado em 1981, inspirado no discurso de Sojourner Truth.
} 
empenho das mulheres negras para serem sujeitos políticos, criando discursos contra-hegemônicos.

A discussão sobre a pluralidade feminina, sobre desconsiderar a sua universalização, já ocorria no século XIX. O feminismo hegemônico já se deparava com esse impasse, isto é, deveria considerar outras intersecções, como raça, gênero e classe social. A fala de Truth nos mostra que muito antes, no período escravocrata, e com a contribuição das feministas negras essa discussão já estava sendo realizada, contudo sem muita visibilidade. Assim, a partir da primeira onda e consequentemente na segunda onda, tal debate já era existente. Isto posto, bell hooks (2019) argumenta porque se deve colocar mulheres negras no centro.

[...] o público que eu mais queria alcançar eram as mulheres negras, que eu queria nos colocar no centro [...]. Minha postura de colocar mulheres negras no centro não foi uma ação para excluir as outras; foi, ao contrário, um convite, um desafio para aqueles que nos ouviram falar, para mudar paradigmas ao invés apropriar, para fazer todos os leitores ouvirem a voz de uma negra falando de um assunto. (hooks, 2019, p.51)

As mulheres negras não querem somente falar, elas querem ser. "Para mulheres negras, nossa luta não tem sido para emergir do silêncio para a fala, mas para mudar a natureza e a direção da nossa fala, para fazer uma fala que atraia ouvintes, que seja ouvida" (hooks, 2019, p.32-33). É preciso que se reconheça a existência de uma multiplicidade de vozes, e sobretudo desconstruir e romper com o discurso único e legitimado, que se pensa absoluto.

O feminismo negro não é atual, pois já se trabalha com um legado que vem oficialmente desde a década de 1970. Nessa época já havia mulheres negras atuando como feministas, embora não se assumissem ou não soubessem que estavam sendo feministas, não tendo consciência disso. $\mathrm{O}$ feminismo negro surge para que a mulher negra seja vista como um sujeito político que participa das questões sociais, econômicas e, sobretudo, para que a mulher negra seja vista como um ser humano, pois ao longo da história foi sempre tratada como inferior, como inexistente, ocupando um não lugar social, que é o lugar da invisibilidade, do silenciamento. Para hooks,

Fazer a transição do silêncio à fala é, para o oprimido, o colonizado, o explorado, e para aqueles que se levantam e lutam lado a lado, um gesto de desafio que cura, que possibilita uma vida nova e um novo crescimento. Esse ato de fala, de "erguer a voz", não é um mero gesto de palavras vazias: é uma expressão de nossa transição de objeto para sujeito - a voz liberta. (hooks, 2019, p.38-39)

A socióloga estadunidense Patricia Hill Collins, em seu artigo "Aprendendo com o outsider within: a significação sociológica do pensamento feminista negro" (2016), publicado originalmente em 1986, ratifica que falar a partir das mulheres negras é uma proposição 
fundamental para o feminismo negro, pois, já que há uma visão colonizadora acerca dos corpos, saberes e produção da população negra, é preciso contestar esse olhar. A respeito do lugar do Outro e sobre a urgência de mulheres negras de se autodefinirem Collins afirma que:

\begin{abstract}
A insistência de mulheres negras autodefinirem-se, autoavaliarem-se e a necessidade de uma análise centrada na mulher negra é significativa por duas razões: em primeiro lugar, definir e valorizar a consciência do próprio ponto de vista autodefinido frente a imagens que promovem uma autodefinição sob a forma de "outro" objetificado é uma forma importante de se resistir à desumanização essencial aos sistemas de dominação. O status de ser o "outro" implica ser o outro em relação a algo ou ser diferente da norma pressuposta de comportamento masculino branco. Nesse modelo, homens brancos poderosos definem-se como sujeitos, os verdadeiros atores, e classificam as pessoas de cor e as mulheres em termos de sua posição em relação a esse eixo masculino branco. Como foi negada às mulheres negras a autoridade de desafiar essas definições, esse modelo consiste de imagens que definem as mulheres negras como um outro negativo, a antítese virtual da imagem positiva dos homens brancos. (COLLINS, 2016, p. 105.)
\end{abstract}

Para a autora é importante que as mulheres negras utilizem de modo criativo o lugar de "marginalidade" no qual estão inseridas na sociedade com a finalidade de criarem teorias para se pensar distintos olhares sobre esses sujeitos, além de delimitar possibilidades de se transcender com a norma colonizadora.

Conforme Collins, a mulher negra dentro do movimento feminista ocupa esse lugar de outsider within ("forasteira de dentro"), pelo de fato de esforçar-se em ocupar o lugar da mulher sujeito político, e concomitantemente ela é uma "uma de fora" pela forma que a enxergam e a tratam dentro do próprio movimento feminista, e também pela maneira como as reivindicações do movimento eram realizadas. Collins caracteriza outsider within como condição social ou lugares fronteiriços povoados por grupos que possuem poder desigual.

bell hooks (1995, p. 468) afirma que "as intelectuais negras trabalhando em faculdades e universidades enfrentam um mundo que os de fora poderiam imaginar que acolheria nossa presença, mas que, na maioria das vezes, encara nossa intelectualidade com suspeita”. É fato que as mulheres negras não são as únicas a enfrentarem problemas sociais gerados por gênero, raça, classe, nacionalidade, idade, sexualidade e sistemas análogos de opressão. As experiências das mulheres negras quando consideradas em conjunto revelam porque as ideias mantêm-se sendo essenciais para as lutas por igualdade e liberdade. A resistência das mulheres negras tem se empenhado em reivindicar o seu lugar de direito como sujeitos integralmente humanos. As mulheres negras resistem, ora partilhando momentos afetuosos uma com as outras cotidianamente, ora criticando as políticas públicas que negam acesso à educação, saúde, segurança, moradia, entre outras.

Isto posto, ser mulher negra no Brasil é ter consciência que se está em uma posição de desvantagem histórica. Ser mulher negra é não se reconhecer na TV, não se reconhecer 
como protagonista nas obras literárias, no cinema, é ter o corpo hipersexualizado, e pensando nas grandes mídias e nos livros escolares, as referências são essas.

Dentro dessa perspectiva, entende-se que as mulheres negras enfrentam ainda desafios como lidar com a herança da escravidão que desvaloriza a condição da mulher negra, tal qual criar respostas ao racismo que toma contornos distintos de acordo com o gênero. Entretanto, não se deve afirmar que as histórias dessas mulheres são as mesmas, que o feminismo negro produzido por elas também é igual. Os contornos que o racismo assumiu nas sociedades formadas sobretudo por colonizadores brancos se revelaram distintos, do mesmo modo que as relações das mulheres negras com elas mesmas.

Não é necessário ser uma mulher negra para entender de que modo o ativismo intelectual pode gerar novos saberes, novas ideias, novos conhecimentos e alterar a consciência, podendo impulsionar uma política de empoderamento, em que se empoderar reivindica mais que modificar a consciência individual das mulheres negras mediante artifícios de desenvolvimento da comunidade negra. Além disso, o empoderamento requer mudanças nas desigualdades sociais que se perpetuam de geração a geração.

De acordo com bell hooks, para a mulher negra

[...] a fala verdadeira não é somente uma expressão de poder criativo; é um ato de resistência, um gesto político que desafia políticas de dominação que nos conservam anônimos e mudos. Sendo assim, é um ato de coragem -e, como tal, representa uma ameaça. Para aqueles que exercem o poder opressivo, aquilo que é ameaçador deve ser necessariamente apago, aniquilado e silenciado. (hooks, 2019, p.36-37)

Para bell hooks a linguagem é também um lugar de embate pois “o oprimido luta na linguagem para recuperar a si mesmo - para reescrever, reconciliar, renovar. Nossas palavras não são sem sentido. Elas são uma ação - uma resistência. A linguagem é também um lugar de luta" (hooks, 2019, p.73-74). Ademais, é fundamental para se criar uma voz libertadora, saber com quem se fala, confrontar o público.

saber quem está ouvindo dá uma indicação de como nossas vozes são ouvidas. Minhas palavras são ouvidas de modo diferente pelos poderosos opressores. São ouvidas de uma maneira diferente por mulheres negras que, como eu, estão lutando para se recompor dos efeitos destrutivos da colonização. Para conhecer nosso público, para saber quem ouve, precisamos estar em diálogo. Devemos falar com, e não somente falar para. Ao ouvir as respostas começamos a compreender se nossas palavras agem para resistir, transformar, mudar. (hooks, 2019, p.52)

Logo, entende-se que opressão e resistência estão intrinsecamente ligados de tal maneira que o modo de uma atinge a da outra. A opressão não é unicamente entendida no 
pensamento, e sim sentida no corpo de várias formas. E não podemos esquecer que voz libertadora da qual fala bell hooks irá incomodar desse modo: "É preciso entender que a voz libertadora irá necessariamente confrontar, incomodar, exigir que ouvintes até modifiquem maneiras de ouvir e ser." (hooks, 2019, p.53)

Podemos afirmar, portanto, que não podemos pensar em gênero sem discutir raça, sem discutir classe. Não podemos discutir o feminismo apenas sob a perspectiva de gênero, necessariamente discutir a questão da mulher é discutir a questão da população negra no Brasil, é discutir sexismo, lesbofobia, homofobia. Muitas vezes acabamos lidando com esses temas dissociadamente ou negando nossas identidades e a partir disso devemos pensar em uma perspectiva interseccional, considerando que a questão negra necessariamente deveria ser uma questão LGBTQ+ (lésbicas, gays, bissexuais, transexuais e queers), uma vez que existem pessoas LGBTQ+ negras, da mesma forma que a questão de raça deveria ser uma pauta do movimento feminista já que existem mulheres negras. Constantemente se insiste com a noção de universalidade, não levando em consideração que as mulheres são diferentes e a diferença não é ruim, ela só é ruim quando ela representa desigualdade. É preciso que se trabalhe a partir das diferenças, como dizem Audre Lorde e Angela Davis, que se pense as diferenças como "fagulhas criativas" e que não se negue insistentemente essas diferenças. Não faz sentido pensar um futuro feminino sem pensar um futuro negro em um país como o Brasil, que carrega uma herança escravocrata, país que foi o último a abolir a escravidão e que criou mecanismos institucionais de exclusão para população negra. De acordo com carneiro (2019, p. 287)

\begin{abstract}
Os efeitos do racismo e do sexismo são tão brutais que acabam por impulsionar reações capazes de recobrir todas as perdas já postas na relação de dominação. $\mathrm{O}$ efervescente protagonismo das mulheres negras, orientado num primeiro momento pelo desejo de liberdade, pelo resgate de humanidade negada pela escravidão e, num segundo momento, pontuado pelas emergências das organizações de mulheres negras e articulações nacionais de mulheres negras, vem desenhando novos cenários e perspectivas para as mulheres negras e recobrindo as perdas históricas.
\end{abstract}

Ademais, é preciso aprofundar esse debate e não colocar a questão do feminismo apenas como uma questão de empoderamento em sentido esvaziado, pois o sentido de empoderamento pela perspectiva do feminismo negro é pensar como as mulheres juntas podem criar formas de enfrentamento às opressões, no sentido sempre de coletividade e que frequentemente acaba sendo esvaziado. É preciso resgatar o sentido real desse conceito e lutar contra o esvaziamento dele, pois os papéis sociais baseados na divisão do trabalho continuam os mesmos. É preciso pensar em formas que interliguem as lutas das mulheres e pensar 
verdadeiramente em uma sociedade transformadora e para isso que tenha uma escuta e a escuta é, portanto, primordial. Os sujeitos que estão em uma posição de privilégio precisam refletir que esse lugar de privilégio representa a opressão de outro grupo e o não fazer nada significa manter esse sujeito no lugar da dor, do sofrimento. Essas pessoas que estão no lugar de privilégio precisam entender que discutir racismo não é uma questão apenas dos negros, que é necessário que as pessoas brancas discutam racismo pelo ponto de vista da branquitude, pelo ponto de vista do poder que significa ocupar esse grupo que vem historicamente se beneficiando. Portanto, é necessário entender que as opressões precisam ser encaradas de maneira interligada e que o incômodo é necessário porque é a partir dele que se deve pensar o que se pode realizar.

\title{
IS RESISTING NEEDED? \\ FEMINISMS AS A FORM OF RESISTANCE TO OPPRESSION
}

\begin{abstract}
This article aims to reflect on the invisibility, silence, struggle and resistance of women, especially black women, since there is an urgency to consider the plurality of feminism. It is emphasized that the intersectionality between the forms of oppression corroborates the collective struggle of black women in their different ways of resisting and in the most varied spheres of power. Black women questioned the behavior of the feminist movement, introducing their categories of struggle. In the midst of this trajectory, they face the lack of recognition of their writings in academia, silencing, historically constructed stereotypes and racism delimiting the social spaces of black women. When faced with the impacts of the epistemicide, black women strengthen the collective battle and indicate the urgency of understanding gender inequalities based on a social whole. That said, when we reveal the contributions of black feminism, we are faced with a multifaceted reality, that is, a reality in which categories such as gender, class and race must be available in order to associate in order to better collaborate for the viability carrying out analyzes that ensure that they cover the complexity that describes the problem in question with greater accuracy. Do we believe that discussions like this are important to reflect on why we have to think about black feminism if it is an agenda that covers all women? We need to think about a process of socialization of black people and white people and the place that these women will occupy not only in social relations, but also in the mode of production. In addition, the countless questions that comprise writing written by women and the transition between silence and speech were considered. In this perspective, this article will bring together the most representative theorists and scholars that supported the research, among them bell hooks (2018; 2019), Collins (2019), Scott (1992), Hollanda (2019), Kilomba (2019), Perrot (1989; 2005), Ribeiro (2018), among others.
\end{abstract}

KEYWORDS: Representation of the Feminine. Resistance. Black Feminism.

\section{REFERÊNCIAS}

BRANDÃO, Ruth Silviano. Mulher ao pé da letra: a personagem feminina. 2. ed. Belo Horizonte: Editora UFMG, 2006.

CARDOSO, Cláudia Pons. Outras falas: feminismos na perspectiva das mulheres negras brasileiras. 383 f. Tese (Doutorado em Estudos Interdisciplinares sobre Mulheres, Gênero e Feminismo) - Universidade Federal da Bahia. Salvador, Bahia, 2012.

CARNEIRO, Sueli. Enegrecer o feminismo a situação da mulher na América Latina. 2011 Disponível em: <http://arquivo.geledes.org.br/em-debate/sueli-carneiro/17473-sueli-carneiroenegrecer-o-feminismo-a-situacao-da-mulher-negra-na-america-latina-a-partir-de-uma-perspectiva-de-genero $>$. Acesso em: 27 jan. 2020. 
Mulheres em Movimento. Estudos Avançados, v. 17, n. 49, p.117-133, 2003. Disponível em: $<$ http:/ /www.scielo.br/scielo.php?script=sci_arttext\&pid=S010340142003000300008> . Acesso em: 11 jan. 2020.

Mulheres em movimento: contribuições do feminismo negro. In.: HOLLANDA, Heloisa Buarque de (Org.). Pensamento feminista brasileiro: formação e contexto Rio de Janeiro: Bazar do Tempo, 2019.

COLLINS, Patricia Hill. Pensamento feminista negro: consciência e a política do empoderamento. 1. ed. São Paulo: Boitempo, 2019. Tradução de Jamille Pinheiro Dias.

Aprendendo com a outsider within: a significação sociológica do pensamento feminista negro. Sociedade e Estado, v. 31, n. 1, p. 99-127, 2016. Disponível em: $<$ http://www.scielo.br/scielo.php?pid=s0102-69922016000100099\&script=sci_abstract\&tlng=pt $>$. Acesso em: 26 jan. 2019.

hooks, bell. Erguer a voz: pensar como feminista, pensar como negra ;. 1. ed. São Paulo: Elefante, 2019. Tradução de Cátia Bocaiuva Maringolo.

. Teoria feminista: da margem ao centro São Paulo: Perspectiva, 2019a. Tradução de Rainer Patriota.

Olhares negros: raça e representação . 1. ed. São Paulo: Elefante, 2019. Tradução de Stephanie Borges.

.Intelectuais negras. Estudos Feministas, n. 2, 1995. Disponível em: <https://www.geledes.org.br/wp-content/uploads/2014/10/16465-50747-1-PB.pdf > . Acesso em: 06 fev. 2020.

KILOMBA, Grada. Memórias da plantação - Episódios de racismo cotidiano 1. ed. Rio de Janeiro: Cobogó, 2019. Tradução Jess Oliveira.

PERROT, Michelle. Práticas da Memória Feminina. Revista Brasileira de História, v. 9, n. 18, p. 9-18, São Paulo, ago-set. 1989. ane Ribeiro. As mulheres ou os silêncios da história. Bauru, SP: EDUSC, 2005. Tradução de Vivi- Minha História das Mulheres. 1. reimpressão. São Paulo: Contexto, 2008. Tradução de Angela M. S. Corrêa.

SCOTT, Joan. História das Mulheres. In. BURKER, Peter. A escrita da história: novas perspectivas. São Paulo: UNESP, 1992.

Recebido em: 28/03/2021.

Aprovado em: 04/06/2021. 